\title{
On the Limitations of Volumetric Energy Density as a Design Parameter for Selective \\ Laser Melting
}

Umberto Scipioni Bertoli $^{\mathrm{a}}$, Alexander J. Wolfer ${ }^{\mathrm{b}}$, Manyalibo J. Matthews ${ }^{\mathrm{c}}$, Jean-Pierre R. Delplanque $^{\mathrm{b}}$, Julie M. Schoenung ${ }^{\mathrm{a}}$

${ }^{a}$ Department of Chemical Engineering and Materials Science, University of California, Irvine, Irvine, CA 92697, United States

${ }^{\mathrm{b}}$ Department of Mechanical and Aerospace Engineering, University of California, Davis, Davis, CA 95616, United States

${ }^{c}$ Materials Science Division, Lawrence Livermore National Laboratory, 7000 East Avenue, Livermore, CA 94550, United States

Corresponding Author: Julie M. Schoenung, Julie.Schoenung@UCI.edu

\begin{abstract}
Energy density is often used as a metric to compare components manufactured with Selective Laser Melting (SLM) under different sets of deposition parameters (e.g., laser power, scan speed, layer thickness, etc.). We present a brief review of the current literature on additive manufacturing of $316 \mathrm{~L}$ stainless steel (SS) related to input parameter scaling relations. From previously published work we identified a range of Volumetric Energy Density (VED) values that should lead to deposition of fully dense parts. In order to corroborate these data, we designed a series of experiments to investigate the reliability of $V E D$ as a design parameter by comparing single tracks of 316L SS deposited with variable deposition parameters. Our results show the suitability of $V E D$ as a design parameter to describe SLM to be limited to a narrow band of
\end{abstract}


applicability, which is attributed to the inability of this parameter to capture the complex physics of the melt pool. Caution should be exercised when using VED as a design parameter for SLM.

Keywords: 316L stainless steel; Powder-bed fusion; Selective Laser Melting; Energy density; keyhole-mode laser melting

\section{Introduction}

The need for manufacturing of complex components that are difficult-to-impossible to fabricate through subtractive methods has increased interest in layer-by-layer manufacturing technologies given their freeform capability to process 3-dimensional parts with minimal material waste. Currently, Selective Laser Melting (SLM), a powder-bed-fusion based process, is arguably one of the most successful of these techniques. In SLM a high-power laser melts metal powders one layer at a time to produce final net-shaped components using a 3D computer-aided design (CAD) model as a guide.

Given the presence of a wide spectrum of custom-made and commercially available SLM systems, the manufacturing of parts is affected by a large number of different deposition parameters, at least 130 according to Yadroitsev (Yadroitsev, 2009). The most commonly investigated parameters are laser power, scanning speed, scanning strategy, hatch distance and layer thickness. These parameters greatly affect the final quality of the material being produced and the literature abounds with correlation studies (both simulation and experimental) between some of these parameters and final properties [(Aboulkhair et al., 2014; Buchbinder et al., 2015; Di et al., 2012; Gong et al., 2015, 2014; Monroy et al., 2013; Wei et al., 2011; Zhang et al., 2013). However, drawing quantitative comparisons between parts fabricated under different conditions can prove challenging. 
Achieving full density in final parts is, for instance, one of the most desired outcomes in additive manufacturing (AM) since the retention of even minimal amounts of residual porosity seriously degrades mechanical properties, which explains the extensive experimental results available in the literature related to density (Liu et al., 2011; Spierings et al., 2011). Researchers have often presented their results on final part porosity using an approach based on energy density, finding that in many cases when deposition occurs in a specific energy density range, final porosity can be minimized. For instance, Wang et al. (Wang et al., 2011) combined laser power $P$ and scan speed $v$ into linear energy density $\Phi=P / v$ (for a fixed laser beam size) to identify the process window for deposition of Inconel 625 and found that values of $\Phi$ in the range of 1-1.5 lead to the best melting conditions for the tested material. Similarly, Yadroitsev et al. (Yadroitsev et al., 2012) in their work on 904L stainless steel optimized the $P / v$ ratio and correlated it with track shape (height, width and depth). In their analysis of single tracks made of maraging steel, Campanelli et al. (Campanelli et al., 2014) combined power, scan speed and laser beam diameter $\sigma$ in the definition of surface energy density $E_{d}=P / v \sigma$ finding that an increase in energy density resulted in a melt pool that was both wider and deeper. A slightly different approach was then followed by Ciurana et al. (Ciurana et al., 2013) where Volumetric Energy Density (VED) was used as a summarizing physical quantity to characterize shape stability of CoCrMo single tracks. Ciurana's definition of $V E D$ is expressed in Eq. 1:

$$
V E D=\frac{P}{v \sigma t}\left[\frac{J}{m m^{3}}\right]
$$

Defined as the ratio between laser power $P$ and the product of scan speed $v$, laser beam diameter $\sigma$ and powder bed layer thickness $t, V E D$ expresses the amount of energy delivered per unit volume of powder deposited in the bed. Ciurana found that a minimum $V E D$ value of $151 \mathrm{~J} / \mathrm{mm}^{3}$ 
was required for efficient melting of CoCrMo powder into continuous single tracks. Similarly, Gong et al. (Gong et al., 2015, 2014) applied volumetric energy density on the analysis of Ti$6 \mathrm{Al}-4 \mathrm{~V}$ alloy, but in their work the value used for $\sigma$ was the hatch distance between two adjacent lines. Gong's results showed a correlation between VED values and internal porosity in final parts, demonstrating that it is possible to minimize residual porosity when deposition takes place in a precise $V E D$ window. When the energy delivered to the powder bed is insufficient, in fact, the poor melting conditions will lead to the retention of a high number of macroscopic pores (from tens to hundreds of microns in size) in the final parts. These pores led to deleterious effects on mechanical properties such as tensile strength and fatigue resistance. When the energy density is instead too high, a deposition condition known as "keyhole mode" is reached: in this mode the melt pool is very deep and re-melting of multiple layers occurs. Due to the high energy density, metal boiling temperatures are reached and vaporization of the alloy takes place. In addition, intense inward Marangoni flow in the melt pool can occur, adding to the propensity for vapor driven gas bubbles to be trapped and increase part porosity (King et al., 2014).

In a recent study by Yap et al. (Yap et al., 2016), VED values used by different authors were compared with the theoretical energy requirements for melting the alloys studied. In most cases, the energy provided to the powder bed was approximately four times the amount theoretically required. Table 1 summarizes some $V E D$ values and their corresponding parameters from previous work on 316L SS found in the literature. VED values were either provided by the authors or calculated on the basis of Eq. 1. According to Table 1 it appears that for 316L, VED values in the range of $100-1000 \mathrm{~J} / \mathrm{mm}^{3}$ are high enough to allow the deposition of stable and continuous tracks that should lead to fully dense parts. Values higher than $1000 \mathrm{~J} / \mathrm{mm}^{3}$ lead to 
inefficient deposition and energy waste and could potentially enter the undesirable keyhole regime.

Table 1 - SLM parameters and energy density for fully dense 316L stainless steel

\begin{tabular}{|c|c|c|c|c|c|c|}
\hline Source & $\begin{array}{l}\text { Laser } \\
\text { power } \\
(\mathrm{W})\end{array}$ & $\begin{array}{l}\text { Scan } \\
\text { speed } \\
(\mathrm{mm} / \mathrm{s})\end{array}$ & $\begin{array}{l}\text { Laser } \\
\text { beam } \\
\text { size }(\mu \mathrm{m})\end{array}$ & $\begin{array}{l}\text { Layer } \\
\text { thickness } \\
(\mu \mathrm{m})\end{array}$ & $\begin{array}{l}V E D \\
\text { range for } \\
\text { fully dense } \\
\text { parts } \\
\left(\mathrm{J} / \mathbf{m m}^{3}\right)\end{array}$ & Sample type \\
\hline $\begin{array}{l}\text { (Wei et al., } \\
\text { 2011) }\end{array}$ & $40-98$ & $30-300$ & 30 & 100 & 155.5 & $\begin{array}{l}\text { - Single tracks } \\
\text { - Single layer } \\
\text { ribbons } \\
\text { - Cubic samples }\end{array}$ \\
\hline $\begin{array}{l}\text { (Di et al., } \\
\text { 2012) }\end{array}$ & $50-150$ & $30-400$ & 70 & 35 & $245-1225$ & $\begin{array}{l}\text { - Single tracks } \\
\text { - Cubic samples }\end{array}$ \\
\hline $\begin{array}{l}\text { (Kamath et al., } \\
\text { 2014) }\end{array}$ & $150-400$ & $500-1800$ & 54 & $0-200$ & $92-155$ & $\begin{array}{l}\text { - Single tracks } \\
\text { - 3D pillars }\end{array}$ \\
\hline $\begin{array}{l}\text { (Cherry et al., } \\
\text { 2015) }\end{array}$ & 180 & Static pulses & 70 & 50 & 105 & - Cubic samples \\
\hline
\end{tabular}

The same value of $V E D$ can be obtained using significantly different deposition parameters, yet no information can be currently found in the literature that provides a comparison between parts obtained with constant $V E D$ values but under different conditions. In view of the above discussion it is the objective of the present study to ascertain the validity of using $V E D$ as a design parameter for SLM deposition, especially to evaluate the lower threshold value ( 100 $\mathrm{J} / \mathrm{mm}^{3}$ ) by depositing single tracks in proximity of this threshold and by comparing their morphology and melting conditions. 


\section{Materials and Methods}

Gas-atomized Micro-Melt® 316L stainless steel powder was purchased from Carpenter Powder Products with a specified particle size range between 16 and $45 \mu \mathrm{m}$. Powder morphology was investigated with scanning electron microscopy (SEM, FEI-XL30). Figure 1 shows that most of the particles are spherical in shape with occasional agglomerates formed through necking. Mechanical sieving of the powder confirmed the particle size range specified by the supplier.

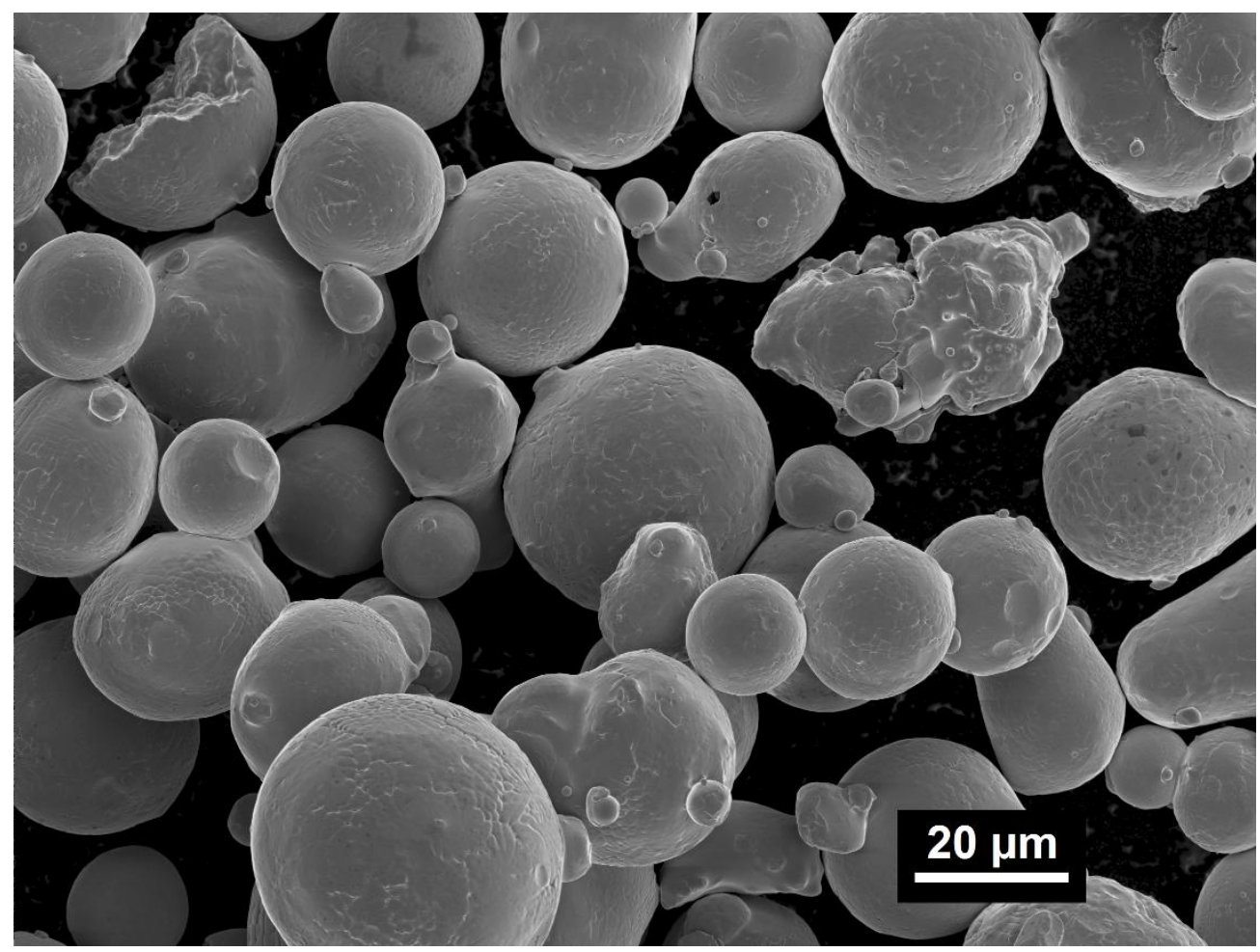

Figure 1 - The gas-atomized particles of 316L SS used in the present study have mostly spherical shape but also exhibit occasional agglomerates.

Deposition experiments were performed at Lawrence Livermore National Laboratory with a custom SLM system. A $1070 \mathrm{~nm}$ Yb fiber laser was used, which can provide power as high as $540 \mathrm{~W}$ at the sample plane and can be scanned using a pair of galvanometer mirrors at speeds up to $5 \mathrm{~m} / \mathrm{s}$. A $450 \mathrm{~mm}$ focusing lens was used to focus a nearly Gaussian beam down to a $55 \mu \mathrm{m}$ $1 / \mathrm{e}^{2}$ diameter circular beam. 
The powder was manually spread onto a 316L SS 1" diameter circular substrate that had been previously grit-blasted to promote track adhesion. A series of straight $3 \mathrm{~mm}$-long single tracks was deposited through the variation of laser power and scan speed. Laser power was linearly increased by $100 \mathrm{~W}$ increments from 100 to $500 \mathrm{~W}$, and six different tracks were deposited with increasing speeds for each value of laser power. Appropriate speed values were chosen for each series in order to obtain the same $V E D$ values, allowing for ease of comparison. Thirty single tracks were deposited with a constant layer thickness of $75 \mu \mathrm{m}$. The deposition parameters and corresponding VED values are summarized in Table 2. High resolution 3-D images of the deposited tracks were acquired using a Zeiss Axio CSM 700 confocal microscope.

Table 2 - SLM deposition parameters and corresponding Volumetric Energy Density (VED) values, computed according to Eq. 1. Beam diameter was kept constant at $55 \mu \mathrm{m}$.

\begin{tabular}{|c|c|c|c|c|c|c|}
\hline & $\begin{array}{l}\text { Laser } \\
\text { Power } \\
100 \text { W } \\
\end{array}$ & $\begin{array}{l}\text { Laser } \\
\text { Power } \\
200 \text { W } \\
\end{array}$ & $\begin{array}{l}\text { Laser } \\
\text { Power } \\
300 \text { W } \\
\end{array}$ & $\begin{array}{l}\text { Laser } \\
\text { Power } \\
400 \text { W } \\
\end{array}$ & $\begin{array}{l}\text { Laser } \\
\text { Power } \\
500 \text { W } \\
\end{array}$ & $\begin{array}{c}V E D \\
\left(\mathrm{~J} / \mathrm{mm}^{3}\right)\end{array}$ \\
\hline \multirow{6}{*}{ 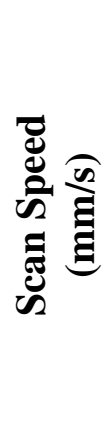 } & 100 & 200 & 300 & 400 & 500 & 242 \\
\hline & 150 & 300 & 450 & 600 & 750 & 162 \\
\hline & 200 & 400 & 600 & 800 & 1000 & 121 \\
\hline & 250 & 500 & 750 & 1000 & 1250 & 97 \\
\hline & 300 & 600 & 900 & 1200 & 1500 & 81 \\
\hline & 500 & 1000 & 1500 & 2000 & 2500 & 48 \\
\hline
\end{tabular}

The substrate with the single tracks was cut with wire-electrical discharge machining (wireEDM) and mounted for cross-section analysis. Metallographic grinding was performed with silicon carbide papers (320 to 1200 grit size) followed by manual polishing with diamond suspensions $(3 \mu \mathrm{m}$ and $1 \mu \mathrm{m})$ and final precision polishing with silica suspension $(0.04 \mu \mathrm{m})$. Track width and height were measured on the images acquired with both the Zeiss Axio CSM 
700 confocal microscope and the FEI-XL30 SEM. Melt pool penetration into the substrate was also measured from the cross-section images. Since melt pool lines are not visible after polishing, etching was necessary: the etchant used was a 3:1 volume mixture of $\mathrm{HCl}$ and $\mathrm{HNO}_{3}$. Melt pool depth was measured using optical microscopy (Nikon Optiphot - POL).

\section{Results}

\subsection{Track morphology}

Confocal images of the deposited tracks are shown in Fig. 2. The tracks are grouped and labeled with letters from $a$ to $e$ indicating increasing laser powers (from $100 \mathrm{~W}$ to $500 \mathrm{~W}$ ). Laser scan speed is highlighted next to each track, increasing for each sub-figure from top to bottom. As previously observed by others (Ciurana et al., 2013) and further confirmed by this experiment, variation of deposition parameters led to different track morphologies, commonly categorized into three main regimes: continuous, irregular, balling. Three of the tracks are shown again in Fig. 3 as examples used to explain the categorization: (a) at sufficiently high $V E D$ values, the formation of a nice, smooth, continuous track can be observed (Fig. 3a); (b) at lower VED values the track becomes uneven with a non-homogenous, irregular shape (Fig. 3b); and (c) when the energy density is excessively low, a series of barely connected metal beads, balling, is observed (Fig. 3c) (Li et al., 2011; Tolochko et al., 2004). When producing AM parts, only the continuous regime is desired, as this track shape usually leads to good bonding between adjacent lines and results in minimal porosity within the final part. It is therefore important to identify the correct $V E D$ design space that leads to deposition in this regime. 


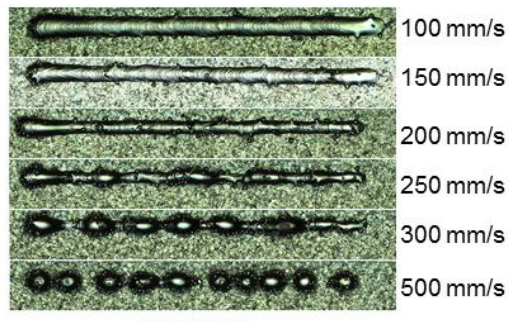

(a) $100 \mathrm{~W}$

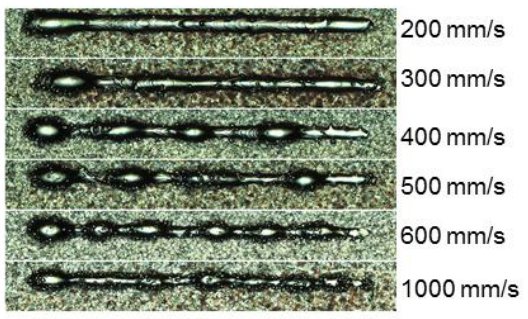

(b) $200 \mathrm{~W}$

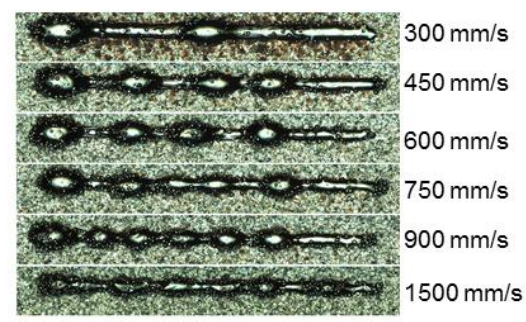

(c) $300 \mathrm{~W}$

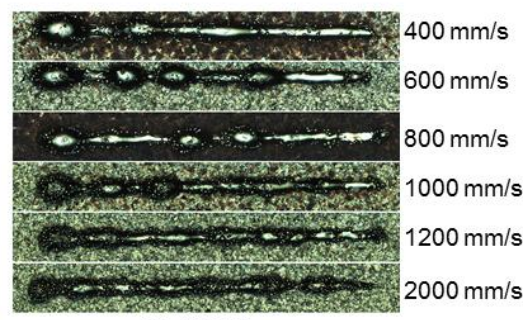

(d) $400 \mathrm{~W}$

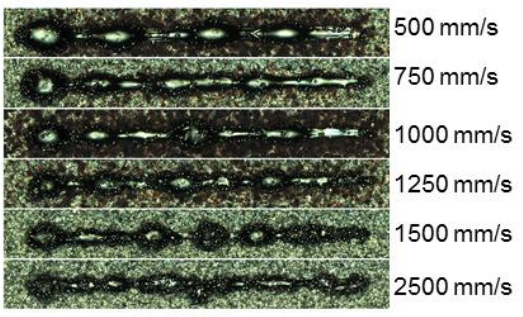

(e) $500 \mathrm{~W}$

$1 \mathrm{~mm}$

Figure 2 - Confocal images of the 30 single tracks of SLM deposited 316L SS. Laser power and scan speed are noted next to the corresponding tracks. Laser spot size $(55 \mu \mathrm{m})$ and layer thickness $(75 \mu \mathrm{m})$ were kept constant throughout the experiment.

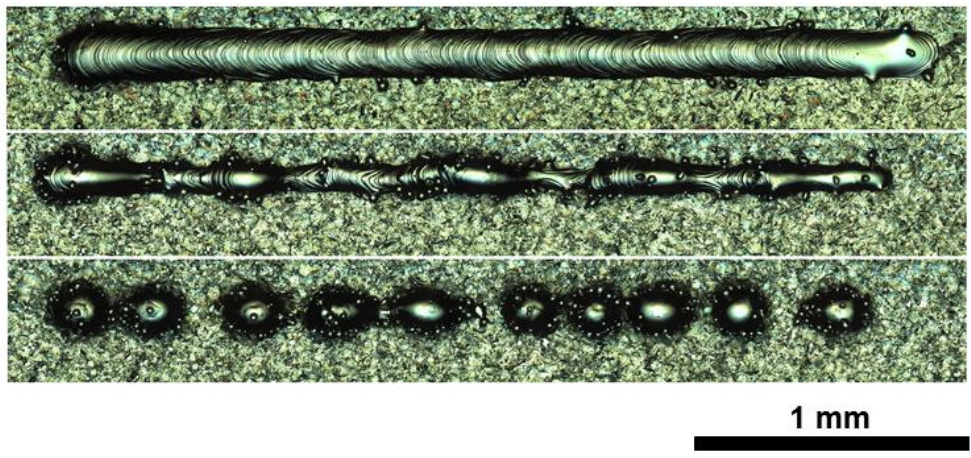

(a) $100 \mathrm{~W}, 100 \mathrm{~mm} / \mathrm{s}, 242 \mathrm{~J} / \mathrm{mm}^{3}$

(b) $100 \mathrm{~W}, 250 \mathrm{~mm} / \mathrm{s}, 97 \mathrm{~J} / \mathrm{mm}^{3}$

(c) $100 \mathrm{~W}, 500 \mathrm{~mm} / \mathrm{s}, 48 \mathrm{~J} / \mathrm{mm}^{3}$

Figure 3 - Observable track shapes: (a) continuous; (b) irregular; (c) balling 


\subsection{Track width and height measurements.}

Results on track geometry from cross-section analysis are heavily dependent on the location of the cross section along the track, especially for single tracks that exhibit irregular morphologies or balling. The advantage of confocal microscopy is that, besides providing an all-in-focus image of the sample, the instrument also yields a 3D reconstruction of the imaged area that allows extrapolation of quantitative data on the sample morphology. Figure 4 illustrates how track height and width were quantified from the confocal images. Track width was averaged from at least six equally spaced measurements taken with ImageJ (ImageJ, n.d.) orthogonal to the track direction and along its length (red arrows in Fig. 4). Track height was quantified along the whole length of the track using the $3 \mathrm{D}$ reconstruction following the dash-dotted blue line. The first $\sim 500 \mu \mathrm{m}$ correspond to the transient regime due to the laser turning on; the scan speed had not yet reached its target value and the excess energy input led to augmented melting of the powder bed causing over-heating and an initial bump in the height profile. The opposite behavior is observed at the end of the track where the laser turns off and the height profile slopes downward with increasing position. Excluding these two transient portions of the track, height was averaged for the $\sim 2000 \mu \mathrm{m}$ long center section (steady state). As observed in Fig. 4, the height profile occasionally shows some acute peaks and valleys: these are noise artifacts due to abnormal light scattering of steep surfaces during the acquisition of the image with the confocal microscope. This phenomenon is clearer in Fig. 5 where the height profile of a track with typical balling morphology $(200 \mathrm{~W}, 400 \mathrm{~mm} / \mathrm{s})$ is shown. The presence of steep ascents and descents due to balling exacerbates noise in the height profile. Nonetheless, wide peaks and valleys are still visible and match visual examination of the features in the corresponding confocal image. As can be expected, when height and width are measured and averaged on samples in the irregular or 
balling regimes, greater uncertainty is obtained and the corresponding error bars are considerably large (see Table 3).

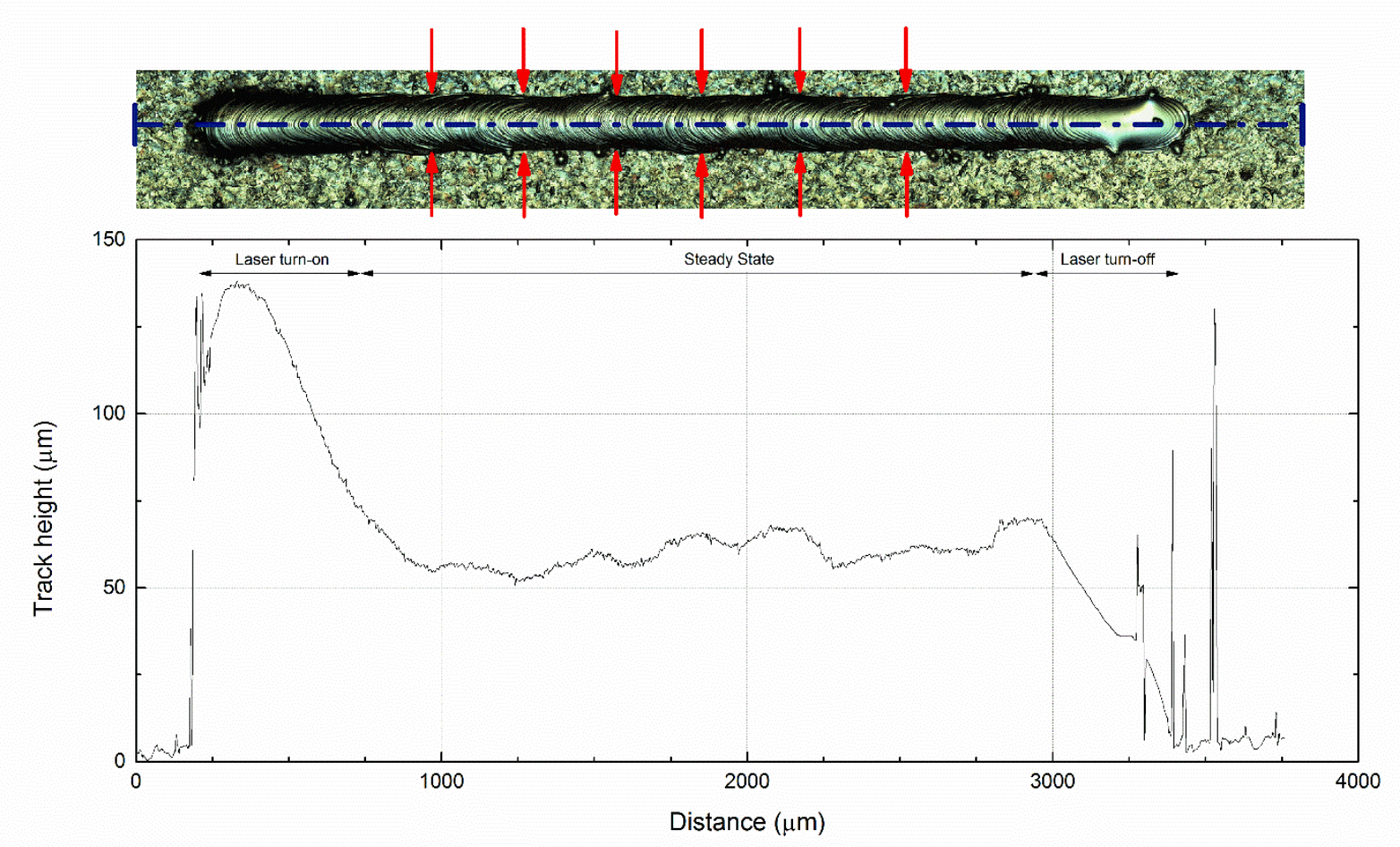

Figure 4 - Top down view of a continuous track $(100 \mathrm{~W}, 100 \mathrm{~mm} / \mathrm{s})$ and matching height profile measured along the dash-dotted blue line with confocal microscopy. The laser is moving from left to right: the initial high peak (distance $\sim 250-750 \mu \mathrm{m}$ on the $\mathrm{x}$ axis) corresponds to the laser turn-on while the final decline (distance $\sim 3000-3500 \mu \mathrm{m}$ on the $x$ axis) matches the laser turn-off. The red arrows show measurement points for track width. 


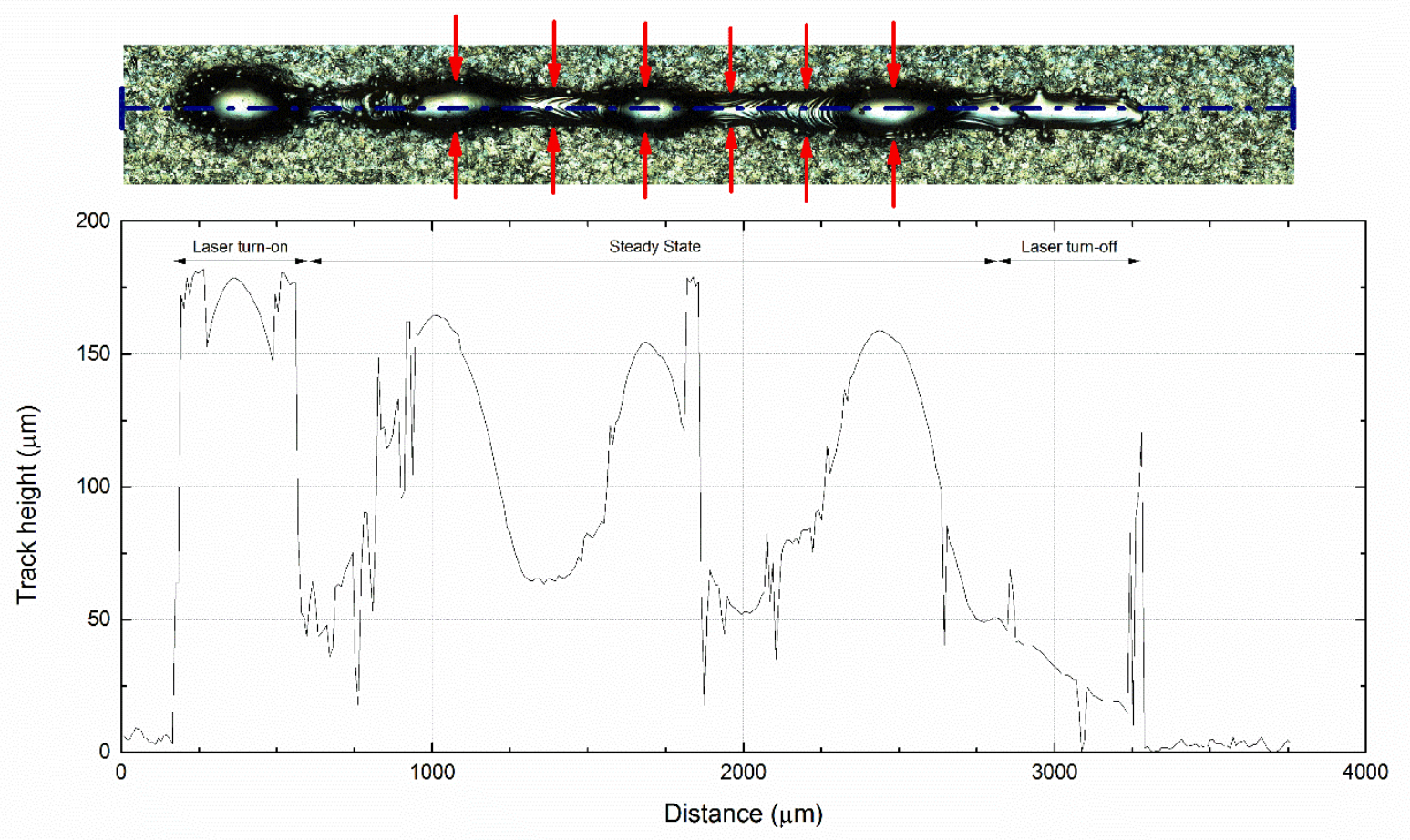

Figure 5 - Top down view of a balling track $(200 \mathrm{~W}, 400 \mathrm{~mm} / \mathrm{s})$ and matching height profile measured along the blue dash-dotted line with confocal microscopy. The laser scanned from left to right: the initial high peak (distance $\sim 200-600 \mu \mathrm{m}$ ) corresponds to the laser turn-on while the final decline (distance $\sim 2750-3250 \mu \mathrm{m})$ matches the laser turn-off. The red arrows show measurement points for track width. Large oscillations (peaks and valleys) due to balling can be observed in the height profile, as well as increased signal noise. 
Table 3 - Track width and height measurements (with standard deviation values) determined from confocal images

\begin{tabular}{|c|c|c|c|c|c|}
\hline $\begin{array}{c}\text { Laser power } \\
(\mathrm{W}), \text { Scan } \\
\text { speed }(\mathrm{mm} / \mathrm{s})\end{array}$ & $\begin{array}{c}\text { Width } \\
(\mu \mathrm{m})\end{array}$ & $\begin{array}{c}\text { Height } \\
(\boldsymbol{\mu m})\end{array}$ & $\begin{array}{c}\text { Laser power } \\
(\mathrm{W}), \text { Scan } \\
\text { speed }(\mathrm{mm} / \mathrm{s})\end{array}$ & $\begin{array}{c}\text { Width } \\
(\mu \mathrm{m})\end{array}$ & $\begin{array}{c}\text { Height } \\
(\mu \mathrm{m})\end{array}$ \\
\hline 100,100 & $176 \pm 8$ & $60 \pm 4$ & 300,750 & $115 \pm 25$ & $70 \pm 31$ \\
\hline 100,150 & $144 \pm 13$ & $54 \pm 11$ & 300,900 & $109 \pm 21$ & $89 \pm 33$ \\
\hline 100,200 & $117 \pm 7$ & $69 \pm 9$ & 300,1500 & $85 \pm 11$ & $71 \pm 26$ \\
\hline 100,250 & $105 \pm 15$ & $69 \pm 25$ & 400,400 & $140 \pm 11$ & $71 \pm 29$ \\
\hline 100,300 & $103 \pm 24$ & $88 \pm 36$ & 400,600 & $130 \pm 27$ & $72 \pm 35$ \\
\hline 100,500 & $133 \pm 14$ & $83 \pm 46$ & 400,800 & $120 \pm 22$ & $52 \pm 32$ \\
\hline 200,200 & $155 \pm 5$ & $73 \pm 15$ & 400,1000 & $111 \pm 20$ & $71 \pm 29$ \\
\hline 200,300 & $130 \pm 10$ & $97 \pm 27$ & 400,1200 & $107 \pm 12$ & $69 \pm 24$ \\
\hline 200,400 & $125 \pm 16$ & $107 \pm 41$ & 400,2000 & $105 \pm 18$ & $80 \pm 24$ \\
\hline 200,500 & $121 \pm 18$ & $101 \pm 43$ & 500,500 & $154 \pm 27$ & $63 \pm 35$ \\
\hline 200,600 & $113 \pm 19$ & $102 \pm 42$ & 500,750 & $122 \pm 14$ & $62 \pm 30$ \\
\hline 200,1000 & $75 \pm 22$ & $94 \pm 31$ & 500,1000 & $121 \pm 36$ & $71 \pm 36$ \\
\hline 300,300 & $138 \pm 17$ & $50 \pm 26$ & 500,1250 & $112 \pm 28$ & $79 \pm 32$ \\
\hline 300,450 & $140 \pm 25$ & $62 \pm 35$ & 500,1500 & $99 \pm 33$ & $92 \pm 40$ \\
\hline 300,600 & $130 \pm 29$ & $67 \pm 41$ & 500,2500 & $87 \pm 17$ & $77 \pm 31$ \\
\hline
\end{tabular}

3.3 Track depth measurements and melting mode transition

After etching the cross-sectioned tracks, the melt pool lines were visible and the re-melting depth can be measured through optical microscopy as the distance between the free surface of the substrate and the bottom of the melt pool, results of which are summarized in Table 4. As observed in the two representative images shown in Fig. 6, two distinct depth profiles were observed, which is consistent with previous studies in the literature (Fabbro and Chouf, 2000; Semak and Matsunawa, 1997). These profiles, and consequently, track depth, are determined by the melting mode: conduction or keyhole. In SLM, if the energy input is sufficiently high, the 
peak temperature in the melt pool $\left(\mathrm{T}_{\max }\right)$ can reach the boiling point $\left(\mathrm{T}_{\mathrm{b}} \sim 3273 \mathrm{~K}\right.$ for $\left.316 \mathrm{~L} \mathrm{SS}\right)$ and vaporization of metal from the melt can occur: this regime is referred to as keyhole melting mode. If the energy input is lower $\left(\mathrm{T}_{\max }<\mathrm{T}_{\mathrm{b}}\right)$, conduction melting mode is observed. The complex physics of keyhole melting, including vaporization and recoil pressure exerted by the vapor on the melt pool, have been recently studied and effectively simulated by Khairallah et al. (Khairallah et al., 2016).

Table 4 - Melt pool depth measured from cross sections using optical microscopy. Melting mode is identified for each track.

\begin{tabular}{|c|c|c|c|c|c|}
\hline $\begin{array}{c}\text { Laser } \\
\text { power } \\
(\mathbf{W}), \text { Scan } \\
\text { speed } \\
(\mathbf{m m} / \mathbf{s})\end{array}$ & $\begin{array}{c}\text { Track } \\
\text { depth } \\
(\mu \mathrm{m})\end{array}$ & Melting mode & $\begin{array}{c}\text { Laser } \\
\text { power } \\
(\mathbf{W}), \text { Scan } \\
\text { speed } \\
(\mathbf{m m} / \mathbf{s})\end{array}$ & $\begin{array}{c}\text { Track } \\
\text { depth } \\
(\mu \mathrm{m})\end{array}$ & Melting mode \\
\hline 100,100 & - & - & 300,750 & 146 & keyhole \\
\hline 100,150 & 150 & keyhole & 300,900 & 128 & keyhole \\
\hline 100,200 & 126 & keyhole & 300,1500 & 50 & conduction \\
\hline 100,250 & 75 & conduction & 400,400 & 597 & keyhole \\
\hline 100,300 & 52 & conduction & 400,600 & 380 & keyhole \\
\hline 100,500 & - & - & 400,800 & 220 & keyhole \\
\hline 200,200 & 329 & keyhole & 400,1000 & 197 & keyhole \\
\hline 200,300 & 266 & keyhole & 400,1200 & 150 & keyhole \\
\hline 200,400 & 159 & keyhole & 400,2000 & 64 & keyhole \\
\hline 200,500 & 118 & keyhole & 500,500 & - & - \\
\hline 200,600 & 70 & conduction & 500,750 & 362 & keyhole \\
\hline 200,1000 & 37 & conduction & 500,1000 & 289 & keyhole \\
\hline 300,300 & 524 & keyhole & 500,1250 & 223 & keyhole \\
\hline 300,450 & 302 & keyhole & 500,1500 & 123 & keyhole \\
\hline 300,600 & 198 & keyhole & 500,2500 & - & - \\
\hline
\end{tabular}


For the samples in the current study, at lower energy input (see for example, Fig. 6a: 100 W, 300 $\mathrm{mm} / \mathrm{s}$ ), the formation of a roughly semi-cylindrical melt pool is obtained where the re-melting depth is usually less than or equal to the powder bed thickness. During the multi-layer SLM deposition of a real part under these circumstances, every layer is therefore re-melted approximately once. When higher energy inputs are delivered to the powder bed instead (see for example, Fig. 6b: $400 \mathrm{~W}, 600 \mathrm{~mm} / \mathrm{s}$ ), the melt pool assumes the shape of a keyhole and its depth/width ratio becomes significantly larger than 1, with penetration into the substrate (or previous layers) reaching depths that can be as high as ten times the single layer thickness.

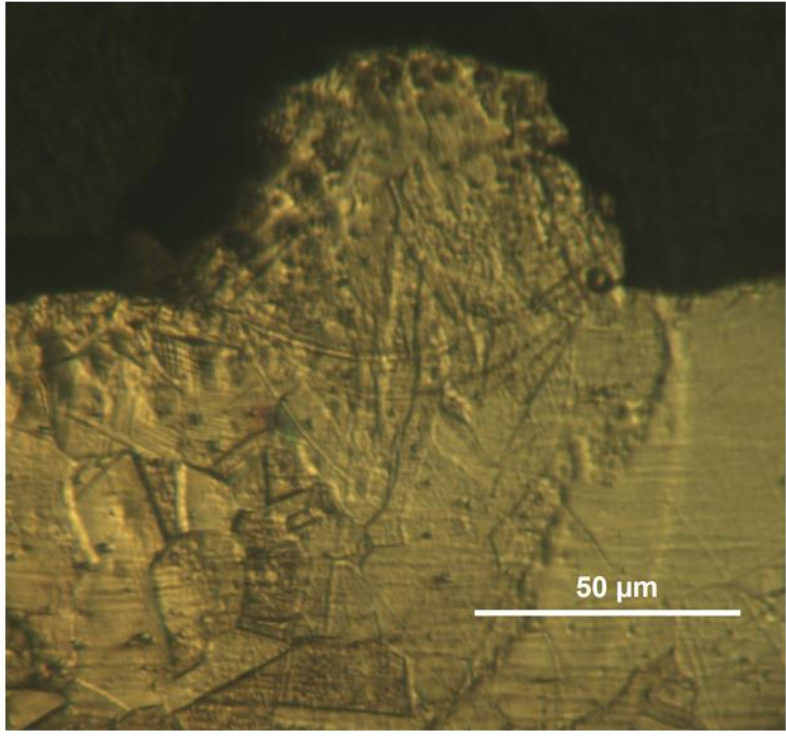

a) Conduction mode

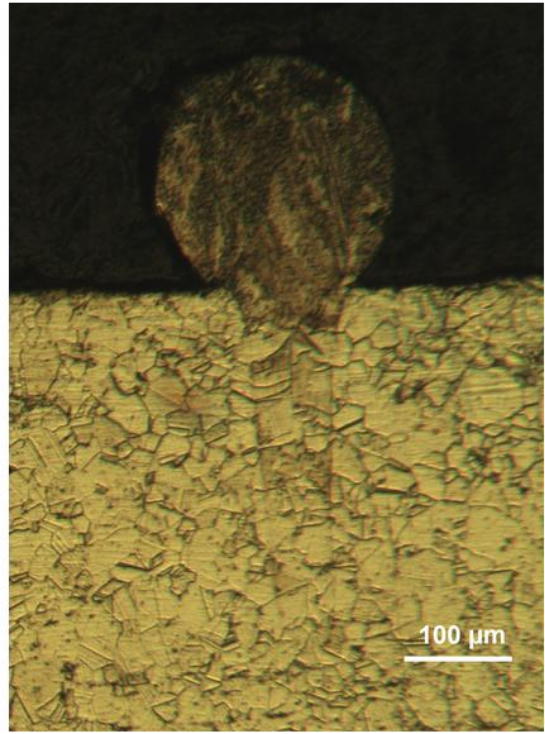

b) Keyhole mode

Figure 6 - Representative images illustrating effect of melting mode (and energy input) on track profile and depth: (a) conduction mode (lower energy inputs: $100 \mathrm{~W}, 300 \mathrm{~mm} / \mathrm{s}$ ) lead to semi-cylindrical shaped melt pools and shallow track depths, (b) keyhole mode (higher energy inputs: $400 \mathrm{~W}, 600 \mathrm{~mm} / \mathrm{s}$ ) lead to keyhole shaped melt pools and deep track depths. 


\section{Discussion}

\subsection{Track shape evolution}

Observation of single tracks deposited with $100 \mathrm{~W}$ laser power (Fig. 2a) corroborates previous findings on optimal VED design space found in the literature (Cherry et al., 2015; Kamath et al., 2014). At low scan speeds of 100, 150 and $200 \mathrm{~mm} / \mathrm{s}$ with corresponding $V E D$ values of 242, 162 and $121 \mathrm{~J} / \mathrm{mm}^{3}$, respectively, full melting of the powder is achieved along with formation of continuous tracks. The $V E D$ values for these tracks lie above the $100 \mathrm{~J} / \mathrm{mm}^{3}$ threshold value found in the literature for successful deposition of fully dense parts (Di et al., 2012; Wei et al., 2011). As scan speed increases to 250 and $300 \mathrm{~mm} / \mathrm{s}$ (VED values of 97 and $81 \mathrm{~J} / \mathrm{mm}^{3}$, respectively), the regime shifts towards an irregular morphology as the track sides appear corrugated and their surface less smooth. The balling regime is eventually reached at a scan speed of $500 \mathrm{~mm} / \mathrm{s}\left(V E D=48 \mathrm{~J} / \mathrm{mm}^{3}\right)$ where a series of separate beads is observed in lieu of a continuous line of solidified metal. A similar trend is found when observing tracks deposited with a laser power of $200 \mathrm{~W}$ (Fig. 2b) with the difference being that now the irregular morphology appears at higher VED values $\left(400 \mathrm{~mm} / \mathrm{s}, V E D 121 \mathrm{~J} / \mathrm{mm}^{3}\right)$ and the optimum VED design space consequently seems to get narrower (or to shift towards higher VED values). Tracks deposited with 300, 400 and $500 \mathrm{~W}$ laser power show the same shift from continuous to irregular/balling regimes at increasingly higher $V E D$ values. This behavior is more clearly observed in Fig. 7 where the five tracks with the highest $V E D$ value $\left(242 \mathrm{~J} / \mathrm{mm}^{3}\right)$ are shown: when higher laser power and faster speed are used, irregular track morphology is observed even though the $V E D$ value is well above the $100 \mathrm{~J} / \mathrm{mm}^{3}$ threshold, it is therefore clear that in this case the use of $V E D$ alone is not sufficient to explain the trend in morphology changes. 


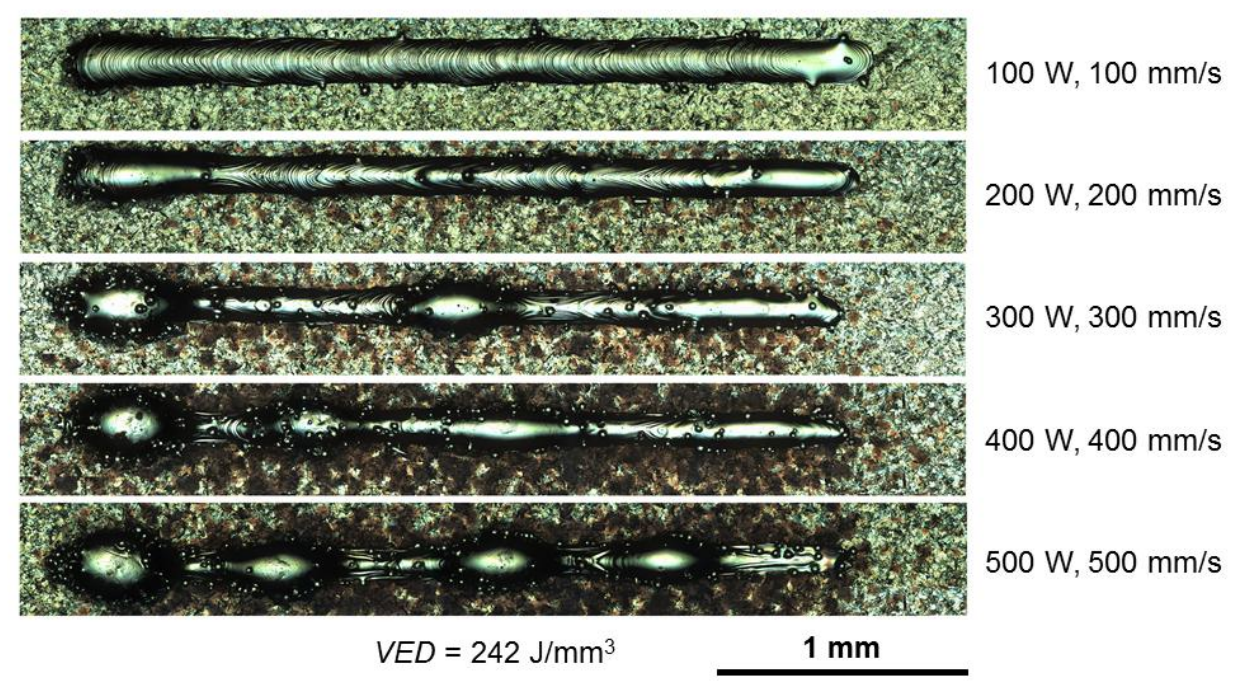

Figure 7 - Five tracks deposited with the same $V E D$ value $\left(242 \mathrm{~J} / \mathrm{mm}^{3}\right)$ but with increasing laser power and scan speed going from top to bottom.

Irrespective of the deposition conditions that lead to it, balling has been argued to be the result of Rayleigh-Plateau capillary instability of the melt pool (Rombouts et al., 2006). The latter can in fact be modeled as a cylinder of liquid metal with diameter $D$ and length $L$, sitting on the powder bed: the condition for instability of such a cylinder is satisfied when its harmonic disturbances have wavelengths comparable to $L$ or, namely, when $L / D>\pi$. Under these conditions, the cylinder minimizes its surface energy by breaking into smaller droplets. In SLM it is well known that both laser power and scan speed affect melt pool shape: for instance, higher scan speed leads to an increase in melt pool length and a decrease in its width. According to Rombouts et al. (Rombouts et al., 2006), as scan speed increases, the melt pool loses its circular shape and becomes more elongated, eventually reaching a comet-like shape. If this elongation becomes too prominent then the Plateau-Rayleigh instability condition is satisfied, hence the melt pool is not 
stable and tends to break into droplets, forming the beads. This explains why deposition at higher scan speed results in an increased tendency to balling. Furthermore, the increase of laser power from $100 \mathrm{~W}$ to $500 \mathrm{~W}$ will lead to an increase in the maximum temperature reached in the powder bed. In the case of a $100 \mathrm{~W}$ laser with a speed of $100 \mathrm{~mm} / \mathrm{s}$, for instance, King's model (King et al., 2014) theoretically predicts a maximum temperature rise of $\Delta \mathrm{T}_{\max } \sim 2580 \mathrm{~K}$, while for a $500 \mathrm{~W}$ laser with $500 \mathrm{~mm} / \mathrm{s}$ scan speed, a value of $\Delta \mathrm{T}_{\max } \sim 7600 \mathrm{~K}$ is obtained. Because the model does not take into account either the latent heat of fusion or vaporization, nor the nonlinear scaling of temperature with laser power when in the keyhole regime, temperature is overestimated. Nonetheless, the values are useful to understand that the physics involved in these two cases can be extremely different. Marangoni convection for instance is the mass transfer along a fluid interface driven by a temperature-induced surface tension gradient and plays a major role in the melt pool dynamics and heat transport, as shown in previous studies (Khairallah et al., 2016; King et al., 2015; Rombouts et al., 2006). For a fixed laser beam size, a melt pool with a higher maximum temperature rise $\Delta T_{\max }$ will generally have a stronger temperature gradient and, in turn, a more intense Marangoni flow that can interact more actively with the melt flow caused by the Plateau-Rayleigh instability.

\subsection{Track height and width}

From the data shown in Table 3, track width is seen to decrease with increasing scan speed at constant laser power. By combining these parameters into VED, Fig. 8 illustrates the correlation between track width and energy input: track width increases in a roughly linear fashion with $V E D$. Furthermore, the five curves (one for each laser power value) are superimposed, highlighting that different values of laser power do not seem to affect track width as long as identical $V E D$ values are used. 


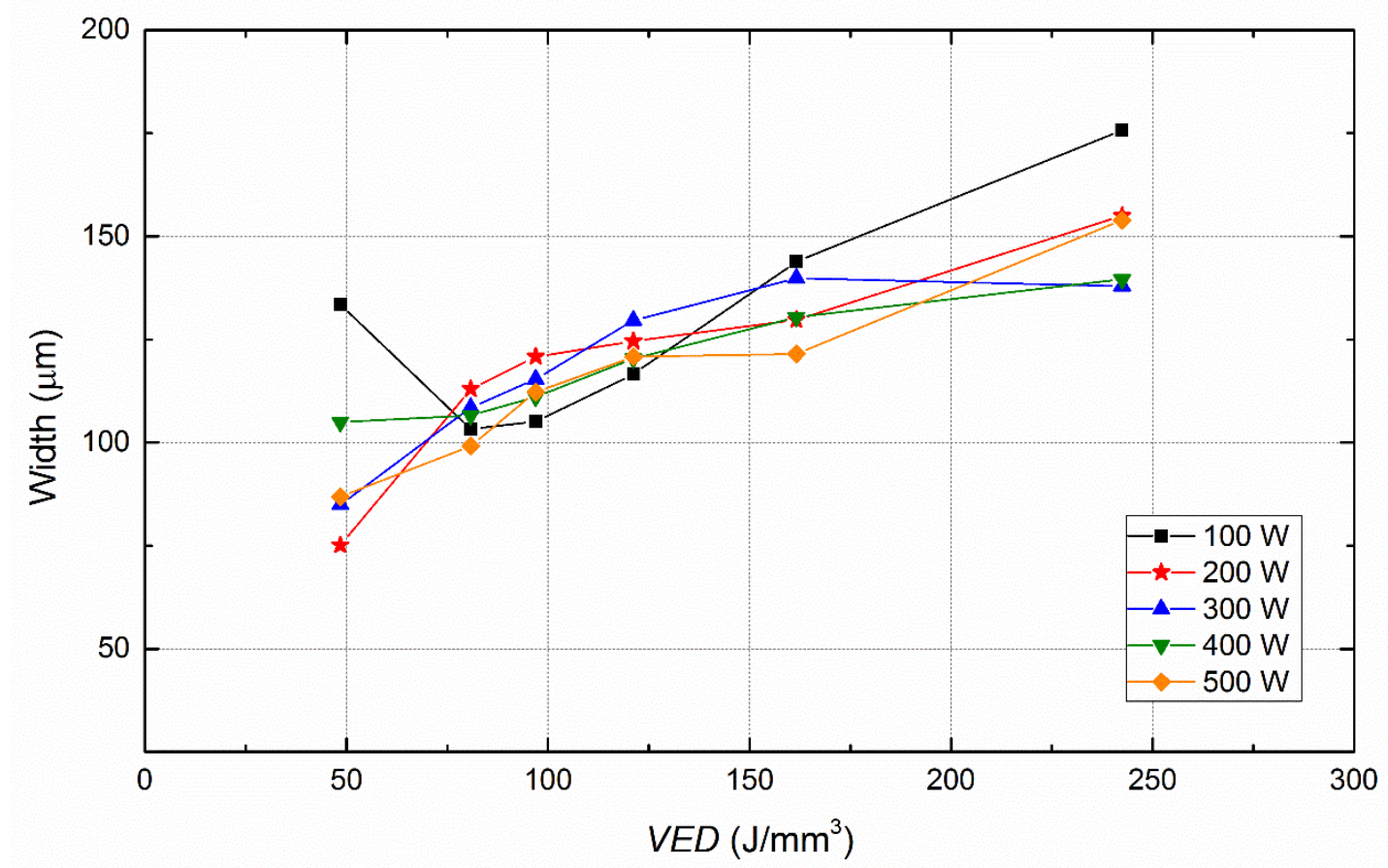

Figure 8 - Track width generally increases with Volumetric Energy Density (VED). Curves obtained with different laser power values are superimposed.

To better understand this trend, it is useful to look at the time scale of different stages of SLM: by means of a simple heat balance the melting time for a $\sim 30 \mu \mathrm{m}$ particle with a $200 \mathrm{~W}$ laser is on the order of a few microseconds, the dwell time of the laser on a fixed point $(\sigma / v)$ is by comparison on the order of tens of microseconds, while heat diffusion time $\left(\sigma^{2} / 4 D\right)$ is much longer and on the order of tens of milliseconds. These values remain valid for most combinations of laser power, spot size, scan speed and particle size. Therefore, as the laser scans over a specific location, the heated particle is melted almost instantaneously and the laser mostly interacts with molten material for the remaining dwell time. Only after several milliseconds will the heat absorbed by the melt pool flow towards the surrounding particles. For each of the five laser power values, when the $V E D$ values are at a minimum (and therefore scan speed is highest), the energy input is barely enough to melt the irradiated powder, which leads to track width values being very close to the laser spot size ( $55 \mu \mathrm{m}$ in our case). The opposite occurs when the 
scan speed decreases: the high temperature of the melt pool due to the excess energy input leads to intense heat flow to nearby particles. These particles melt and will widen the track, thereby explaining the correlation between increasing track width and VED. Figure 9 shows track height as a function of $V E D$. A slight decrease in height is observed as $V E D$ increases, but the curves illustrate the high degree of uncertainty due to the Plateau-Rayleigh instability associated with the tracks that exhibited irregular or balling morphologies.



Figure 9 - Track height weakly decreases with increasing $V E D$. Uncertainty is due to the tracks exhibiting either irregular or balling morphologies.

This instability is seen in both the top-down view images obtained with confocal microscopy shown in Fig. 2 and SEM cross sections (Fig. 10). The six sub-figures of Fig. 10 show the evolution of the height/width ratio as scan speed increases from left to right in samples deposited with $200 \mathrm{~W}$ laser power. Being a result of both Plateau-Rayleigh type instability and poor wettability of the liquid, the minimization of surface energy is evident from left to right as the contact angle increases, causing a change in the cross-section profile from a relatively flat and 
wide profile to a taller and narrower one, confirming previous observations by Zhang et al. (Zhang et al., 2013) and Yadroitsev et al. (Yadroitsev et al., 2010). In many cases the peak height values for the tracks within the balling regime exceeded the powder bed thickness of $75 \mu \mathrm{m}$, which is undesirable as it would cause jamming of the recoating device during a multi-layer process.
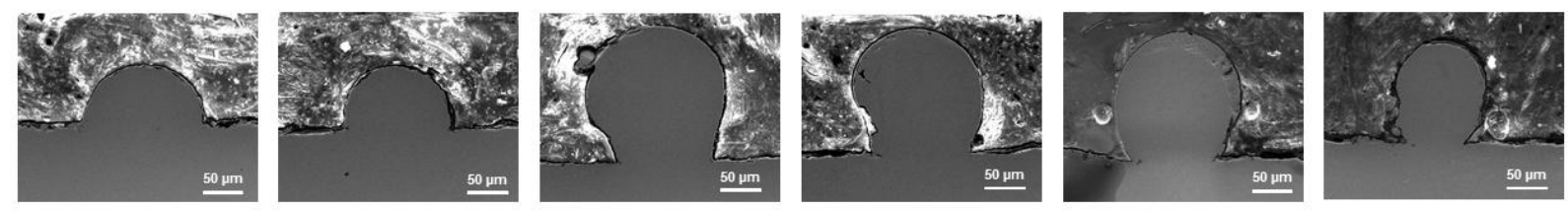

Figure 10 - Cross sections of single tracks deposited with $200 \mathrm{~W}$ laser power. As scan speed increases from left to right $(200,300,400,500,600$ and $1000 \mathrm{~mm} /$, respectively), the aspect ratio evolves as a result of a surface energy minimization driven by Plateau-Rayleigh instability.

\subsection{Track depth and melting mode}

The measured track depths are plotted as a function of $V E D$ values in Fig. 11. Although an approximately linear dependence of track depth on VED value is observed, the track depth is also observed to be a function of laser power. For each curve, solid circles indicate keyhole mode while the open circles indicate conduction mode; since only one cross section was taken per sample, the discrimination between these two melting modes was based on a qualitative assessment of the melt pool shape, rather than on its depth/width ratio. Finally, the shift from conduction mode to keyhole mode is also not captured in Fig. 11 as this transition occurs at a different $V E D$ value for each curve. 


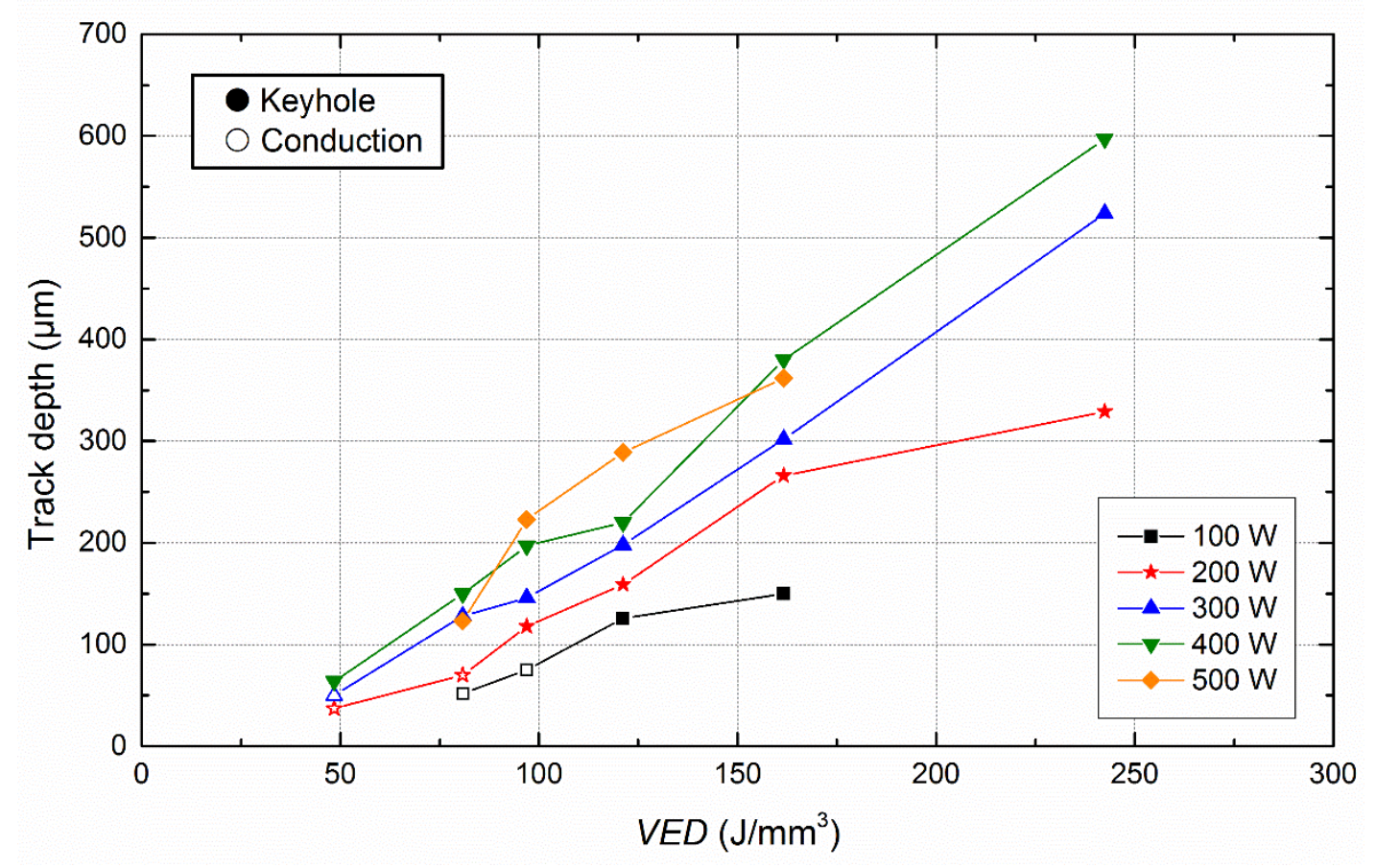

Figure 11 - Track depth increases with Volumetric Energy Density ( $V E D)$ and, at constant $V E D$, deeper penetration is obtained with higher laser power. $V E D$ does not capture the transition between conduction mode (white symbols) and keyhole mode (black symbols) as, for each curve, the transition occurs at a different $V E D$ value.

Previous studies have explored the physical basis for the keyhole transition (Gusarov et al., 2007;

King et al., 2014). To analyze the results in the current study, we focus on the model proposed by

King et al. (King et al., 2014), which was based on previous work carried out on laser weld properties by Hann et al. (Hann et al., 2011) where it was demonstrated that welding data from experiments on different machines and materials could all be represented on one curve since the ratio between the melt depth $d$ and the beam spot size $\sigma$ is a function only of the ratio of the deposited energy density $\Delta H$ to the enthalpy at melting $h_{s}$. According to this model, the ratio $\Delta H / h_{s}$ is defined as

$$
\frac{\Delta H}{h_{s}}=\frac{A P}{\pi h_{s} \sqrt{D v \sigma^{3}}}
$$


where $A$ is the laser absorptivity, $P$ is the laser power, $D$ is the material's thermal diffusivity and $v$ is the laser scan speed. The theoretical threshold value for keyhole mode can be estimated by calculating the deposited energy density $\Delta H$ necessary to heat the 316L powder up to the boiling point. According to (King et al., 2014) the threshold for 316 can be therefore estimated as:

$$
\frac{\Delta H}{h_{s}} \geq \frac{\pi T_{b}}{T_{m}} \approx 6
$$

All the values necessary for computation with Eqs. 2 and 3 were taken from King's work (King et al., 2014). When the measured melt pool depth normalized by laser spot size $d / \sigma$ is plotted as a function of the normalized enthalpy $\Delta H / h_{s}$, the transition from conduction to keyhole becomes evident (Fig. 12). We used a semi-log plot to match the style of (King et al., 2014) and (Hann et al., 2011), which facilitates comparison of the data.

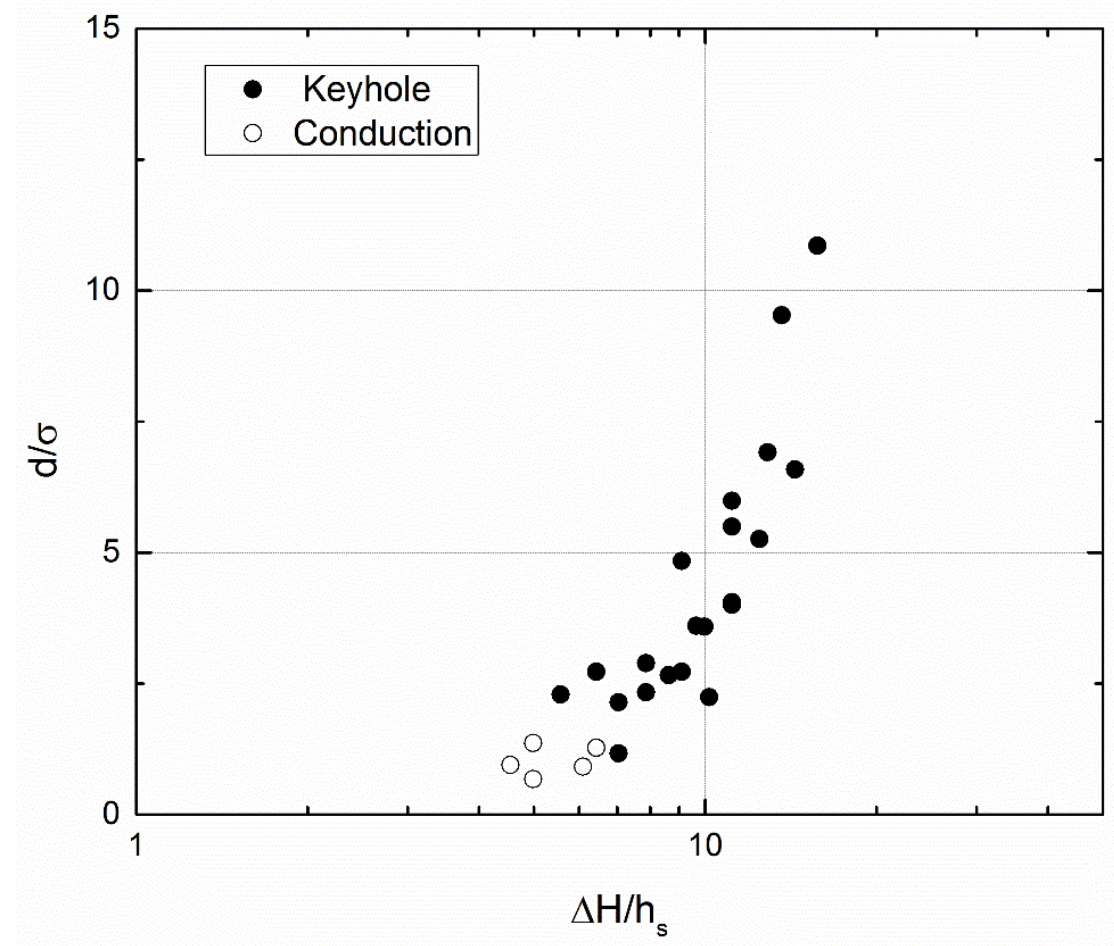

Figure 12 - Normalized melt pool depth is plotted as a function of normalized enthalpy on a semi-log scale. Solid black symbols indicate keyhole melting mode while open white symbols indicate conduction melting mode. 
Analysis of Fig. 11 suggests that melt pool depth can be effectively represented as a function of $V E D$ as a roughly linear dependence is observed. Nevertheless, it is not possible to capture the transition between conduction and keyhole melting as no information is contained in $V E D$ about the nature of melting mode. The curves are also not super-imposed in Fig. 11 since, as stated before, while $V E D$ is kept constant, we observe deeper melt pool with higher laser power. This means that at least one of the parameters that determine $V E D$ (laser power, scan speed, layer thickness, spot size) has a stronger influence on melt pool depth than the others. This is explained as follows: according to Eagar and Tsai (Eagar and Tsai, 1983), the peak temperature reached by a material heated by a Gaussian shaped laser heat source is proportional to the ratio $P / \sqrt{v}$ so that an increase in laser power has a stronger effect on the melting regime than a decrease in scan speed. This explains why the keyhole melting regime is more prevalent at higher laser powers $(300,400$ and $500 \mathrm{~W})$ rather than at lower power $(100,200 \mathrm{~W})$. As can be seen in Eq. 2, the ratio $\Delta H / h_{s}$ is proportional to the $P / \sqrt{v}$ ratio and, as shown in Fig. 12, it successfully captures the melting mode transition between conduction and keyhole. From Fig. 12 , we in fact observe that below a normalized enthalpy value of $\sim 4$, the measured melt pool depth normalized to the beam size is zero and it then increases to $\sim 11$ for a normalized enthalpy value of $\sim 11$. Interestingly, although we observe a transition rather than a sharp distinction, the threshold of keyhole appears to happen at a normalized enthalpy value of $\sim 6$, as predicted by Eq. 3, rather than a value of $\sim 30$ as observed by King et al (King et al., 2014). Furthermore, we do not detect the same degree of scatter in the data in the keyhole regime, probably due to the fact that our highest values of normalized enthalpy $(\sim 11)$ are still quite low compared to King's $(\sim 60)$. 
In light of what has been demonstrated in this work, Volumetric Energy Density (VED) can prove useful in combining the effects of power, speed, layer thickness and beam size to calculate the energy delivered per unit volume of powder bed. It can therefore be effectively compared with the theoretical energy requirements to melt a material (Yap et al., 2016) and serves as a broad guideline for parameter selection.. As such, VED should also prove useful to validate uncertainty quantification models that assess how variability in deposition parameters affects final properties. However, being a mostly thermodynamic quantity, $V E D$ does not capture the kinetics of the melt pool physics and lacks the ability to capture information on the complex science involved in melt pool formation and propagation, as well as mass and heat transfer between the melt pool and the surrounding material such as spattering of molten material (Matthews et al., 2016). VED therefore fails to accurately describe many other properties such as track shape (height and depth) and the resulting melting mode. As a result, a careful and critical approach is highly recommended when exploring new parameter values and when comparing results from experiments done under different conditions.

\section{Conclusions}

In this paper we discussed the use of volumetric energy density (VED) as a key parameter for Selective Laser Melting of 316L stainless steel. It was shown that:

1. Our results confirm that decreasing $V E D$ to values below $100 \mathrm{~J} / \mathrm{mm}^{3}$ by either decreasing laser power or increasing scan speed lead to a degradation of track shape that ultimately enters the balling regime. Furthermore, tracks deposited with sufficiently high VED values (e.g., $242 \mathrm{~J} / \mathrm{mm}^{3}$ ), obtained with increasing laser power and speed, show a transition from the continuous regime to the irregular and balling regimes. 
2. $V E D$ can effectively capture track width evolution. At the lowest $V E D$ values (e.g., 48 $\mathrm{J} / \mathrm{mm}^{3}$ ), the track width reaches its minimum value, approaching the laser spot size $(55 \mu \mathrm{m})$.

3. Depending on the peak temperature, SLM can be carried out in conduction or keyhole mode. In keyhole mode, vaporization of the metal is achieved and the strong recoil pressure creates a deep melt pool with high depth/width ratio and can lead to keyhole porosity. VED is not an appropriate metric to quantify melt pool depth and the threshold between conduction and keyhole. The use of normalized melt pool depth as a function of normalized enthalpy suggested by King et al. (King et al., 2014) is a more appropriate model in describing this transition.

4. $V E D$ is generally a thermodynamic quantity and is therefore not able to capture the complex physics such as Marangoni flow, hydrodynamic instabilities and recoil pressure that drive heat and mass transport in different portions of the melt pool and that, in the end, will dictate final track morphology. 


\section{Acknowledgements}

This work is supported by an Early Stage Innovations grant from NASA's Space Technology Research Grants Program and by LLNL LDRD grant 15-ERD-037, and performed under the auspices of the U.S. Department of Energy by Lawrence Livermore National Laboratory under contract DE-AC52-07NA27344. 
Aboulkhair, N.T., Everitt, N.M., Ashcroft, I., Tuck, C., 2014. Reducing porosity in AlSi10Mg parts processed by selective laser melting. Addit. Manuf. 1-4, 77-86. doi:10.1016/j.addma.2014.08.001

Buchbinder, D., Meiners, W., Wissenbach, K., Poprawe, R., 2015. Selective laser melting of aluminum die-cast alloy - Correlations between process parameters, solidification conditions, and resulting mechanical properties. J. Laser Appl. 27, S29205. doi:10.2351/1.4906389

Campanelli, S.L., Casalino, G., Contuzzi, N., Angelastro, A., Ludovico, A.D., 2014. Analysis of the molten/solidified zone in selective laser melted parts, in: Dorsch, F. (Ed.), . p. 896311. doi:10.1117/12.2042170

Cherry, J.A., Davies, H.M., Mehmood, S., Lavery, N.P., Brown, S.G.R., Sienz, J., 2015. Investigation into the effect of process parameters on microstructural and physical properties of 316L stainless steel parts by selective laser melting. Int. J. Adv. Manuf. Technol. 76, 869-879. doi:10.1007/s00170-014-6297-2

Ciurana, J., Hernandez, L., Delgado, J., 2013. Energy density analysis on single tracks formed by selective laser melting with CoCrMo powder material. Int. J. Adv. Manuf. Technol. 68, 11031110. doi:10.1007/s00170-013-4902-4

Di, W., Yongqiang, Y., Xubin, S., Yonghua, C., 2012. Study on energy input and its influences on singletrack,multi-track, and multi-layer in SLM. Int. J. Adv. Manuf. Technol. 58, 1189-1199. doi:10.1007/s00170-011-3443-y

Eagar, T.W., Tsai, N.S., 1983. Temperature fields produced by traveling distributed heat sources. Weld. J. 62, 346-355.

Fabbro, R., Chouf, K., 2000. Keyhole modeling during laser welding. J. Appl. Phys. 87, 4075. doi:10.1063/1.373033

Gong, H., Rafi, K., Gu, H., Janaki Ram, G.D., Starr, T., Stucker, B., 2015. Influence of defects on mechanical properties of $\mathrm{Ti}-6 \mathrm{Al}-4 \mathrm{~V}$ components produced by selective laser melting and electron beam melting. Mater. Des. 86, 545-554. doi:10.1016/j.matdes.2015.07.147

Gong, H., Rafi, K., Gu, H., Starr, T., Stucker, B., 2014. Analysis of defect generation in Ti-6Al-4V parts made using powder bed fusion additive manufacturing processes. Addit. Manuf. 1-4, 87-98. doi:10.1016/j.addma.2014.08.002

Gusarov, A.V., Yadroitsev, I., Bertrand, P., Smurov, I., 2007. Heat transfer modelling and stability analysis of selective laser melting. Appl. Surf. Sci. 254, 975-979. doi:10.1016/j.apsusc.2007.08.074

Hann, D.B., Iammi, J., Folkes, J., 2011. A simple methodology for predicting laser-weld properties from material and laser parameters. J. Phys. Appl. Phys. 44, 445401. doi:10.1088/0022$3727 / 44 / 44 / 445401$

ImageJ [WWW Document], n.d. URL https://imagej.nih.gov/ij/ (accessed 7.18.16).

Kamath, C., El-dasher, B., Gallegos, G.F., King, W.E., Sisto, A., 2014. Density of additivelymanufactured, 316L SS parts using laser powder-bed fusion at powers up to $400 \mathrm{~W}$. Int. J. Adv. Manuf. Technol. 74, 65-78. doi:10.1007/s00170-014-5954-9

Khairallah, S.A., Anderson, A.T., Rubenchik, A., King, W.E., 2016. Laser powder-bed fusion additive manufacturing: Physics of complex melt flow and formation mechanisms of pores, spatter, and denudation zones. Acta Mater. 108, 36-45. doi:10.1016/j.actamat.2016.02.014

King, W.E., Anderson, A.T., Ferencz, R.M., Hodge, N.E., Kamath, C., Khairallah, S.A., Rubenchik, A.M., 2015. Laser powder bed fusion additive manufacturing of metals; physics, computational, and materials challenges. Appl. Phys. Rev. 2, 41304. doi:10.1063/1.4937809

King, W.E., Barth, H.D., Castillo, V.M., Gallegos, G.F., Gibbs, J.W., Hahn, D.E., Kamath, C., Rubenchik, A.M., 2014. Observation of keyhole-mode laser melting in laser powder-bed fusion additive manufacturing. J. Mater. Process. Technol. 214, 2915-2925.

doi:10.1016/j.jmatprotec.2014.06.005 
Li, R., Shi, Y., Wang, L., Liu, J., Wang, Z., 2011. The key metallurgical features of selective laser melting of stainless steel powder for building metallic part. Powder Metall. Met. Ceram. 50, 141150 .

Liu, B., Wildman, R., Tuck, C., Ashcroft, I., Hague, R., 2011. Investigaztion the effect of particle size distribution on processing parameters optimisation in selective laser melting process. ResearchGate.

Matthews, M.J., Guss, G., Khairallah, S.A., Rubenchik, A.M., Depond, P.J., King, W.E., 2016. Denudation of metal powder layers in laser powder bed fusion processes. Acta Mater. 114, 3342. doi:10.1016/j.actamat.2016.05.017

Monroy, K., Delgado, J., Ciurana, J., 2013. Study of the Pore Formation on CoCrMo Alloys by Selective Laser Melting Manufacturing Process. Procedia Eng. 63, 361-369. doi:10.1016/j.proeng.2013.08.227

Rombouts, M., Kruth, J.P., Froyen, L., Mercelis, P., 2006. Fundamentals of Selective Laser Melting of alloyed steel powders. CIRP Ann-Manuf Technol 55 1:187-192. CIRP Ann. - Manuf. Technol. 55, 187-192. doi:10.1016/S0007-8506(07)60395-3

Semak, V., Matsunawa, A., 1997. The role of recoil pressure in energy balance during laser materials processing. J. Phys. -Appl. Phys. 30, 2541-2552. doi:10.1088/0022-3727/30/18/008

Spierings, A.B., Herres, N., Levy, G., 2011. Influence of the particle size distribution on surface quality and mechanical properties in AM steel parts. Rapid Prototyp. J. 17, 195-202.

Tolochko, N.K., Mozzharov, S.E., Yadroitsev, I.A., Laoui, T., Froyen, L., Titov, V.I., Ignatiev, M.B., 2004. Balling processes during selective laser treatment of powders. Rapid Prototyp. J. 10, 78-87. doi:10.1108/13552540410526953

Wang, L., Wei, Q.S., Shi, Y.S., Liu, J.H., He, W.T., 2011. Experimental Investigation into the SingleTrack of Selective Laser Melting of IN625. Adv. Mater. Res. 233-235, 2844-2848. doi:10.4028/www.scientific.net/AMR.233-235.2844

Wei, Q.S., Zhao, X., Wang, L., Li, R.D., Liu, J., Shi, Y.S., 2011. Effects of the Processing Parameters on the Forming Quality of Stainless Steel Parts by Selective Laser Melting. Adv. Mater. Res. 189193, 3668-3671. doi:10.4028/www.scientific.net/AMR.189-193.3668

Yadroitsev, I., 2009. Selective laser melting. LAP LAMBERT Academic Publishing.

Yadroitsev, I., Gusarov, A., Yadroitsava, I., Smurov, I., 2010. Single track formation in selective laser melting of metal powders. J. Mater. Process. Technol. 210, 1624-1631. doi:10.1016/j.jmatprotec.2010.05.010

Yadroitsev, I., Yadroitsava, I., Bertrand, P., Smurov, I., 2012. Factor analysis of selective laser melting process parameters and geometrical characteristics of synthesized single tracks. Rapid Prototyp. J. 18, 201-208. doi:10.1108/13552541211218117

Yap, C.Y., Chua, C.K., Dong, Z.L., 2016. An effective analytical model of selective laser melting. Virtual Phys. Prototyp. 11, 21-26. doi:10.1080/17452759.2015.1133217

Zhang, B., Dembinski, L., Coddet, C., 2013. The study of the laser parameters and environment variables effect on mechanical properties of high compact parts elaborated by selective laser melting $316 \mathrm{~L}$ powder. Mater. Sci. Eng. A 584, 21-31. doi:10.1016/j.msea.2013.06.055 
